Currículo sem Fronteiras, v. 20, n. 3, p. 1006-1018, set./dez. 2020

\title{
O GERÚNDIO DO GESTO É SEU RASTRO: breves notas sobre o pesquisar com Gonçalo M. Tavares
}

\author{
Anna Leticia Ventre \\ Universidade Federal do Rio Grande do Sul - UFRGS \\ Simone Zanon Moschen \\ Universidade Federal do Rio Grande do Sul - UFRGS
}

\begin{abstract}
Resumo
Este escrito propõe uma experimentação de encontro com a leitura da obra do escritor português Gonçalo M. Tavares, Breves notas sobre a literatura-Bloom: dicionário literário, como um gesto que pode alargar os terrenos do pesquisar. Em composição híbrida, busca colocar em conversa o exercício de experimentação na linguagem via mapas gestuais, escrita resenhal e conexões sobre o escrever como efeito de transitoriedade, um gesto que pulsa em seus rastros.

Palavras-chave: Gesto. Transitoriedade. Literatura. Rastro. Pesquisa.
\end{abstract}

\begin{abstract}
This paper proposes an experiment to find a reading of the work of the Portuguese writer Gonçalo $\mathrm{M}$. Tavares, Brief notes on literature-Bloom: literary dictionary, as a gesture that can broaden the terrain of research. In hybrid composition, he tries to put into conversation the exercise of experimentation in the language via gestural maps, brief writing and connections about writing as an effect of transience, a gesture that pulsates in his traces.
\end{abstract}

Keywords: Gesture. Transience. Literature. Trail. Search.

ISSN 1645-1384 (online) www.curriculosemfronteiras.org

http://dx.doi.org/10.35786/1645-1384.v20.n3.20 


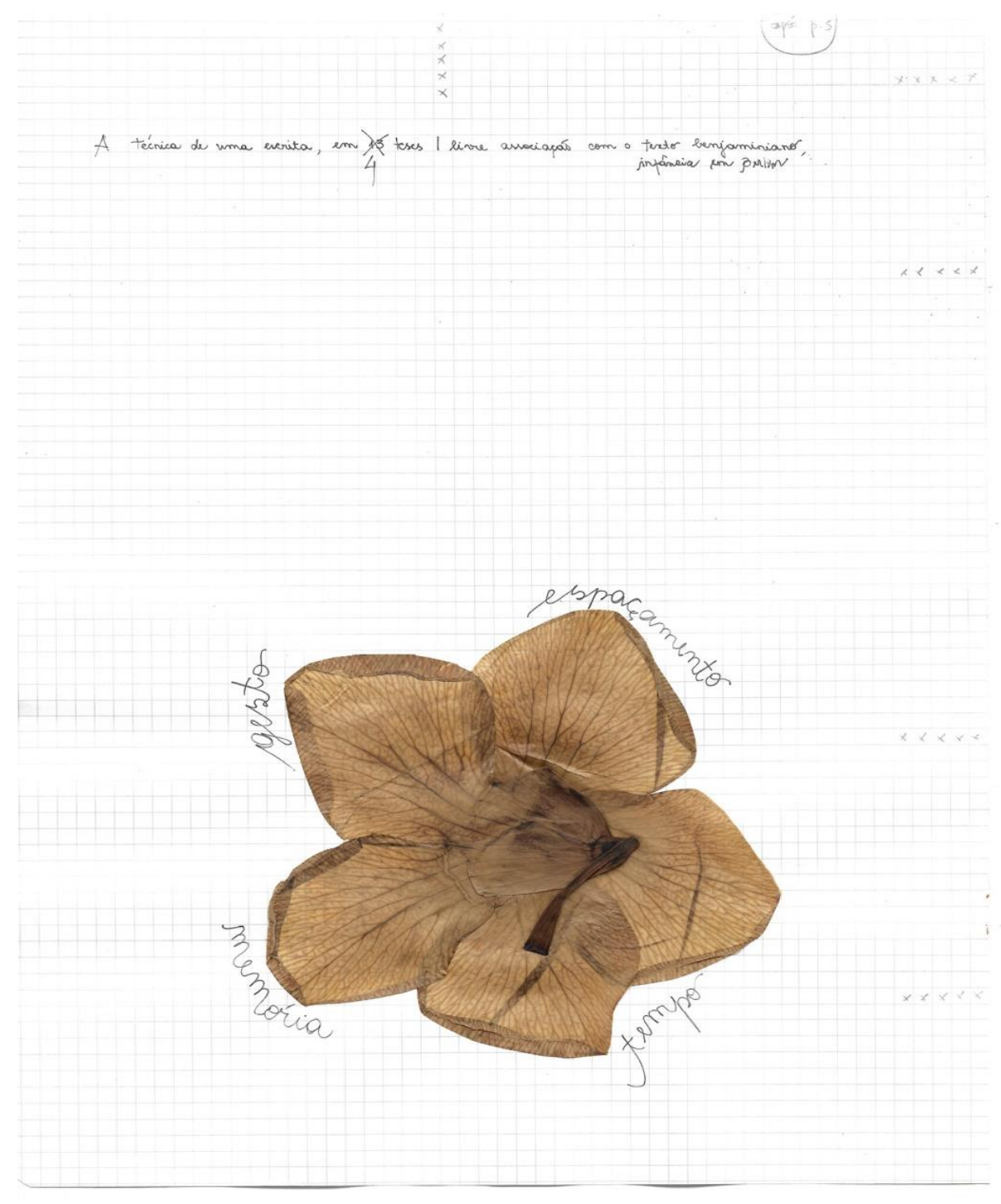

Mapa gestual I: experimentação da pergunta sobre o pesquisar do gesto, aqui, em referência aos efeitos de encontro com Walter Benjamin.

Fonte: Gesto, Rastro, Memória: anotações para pensar uma ética da delicadeza. Dissertação de Mestrado UFRGS, 2018. Disponível em: http://hdl.handle.net/10183/181322.

Quando do aurorear do século XX, Walter Benjamin elabora o que intitula "Técnica do escritor em 13 teses". Diz-em-escrita, quase mirando-nos:

I - Quem quiser lançar-se a escrever uma obra de fôlego, instale-se comodamente e conceda a si próprio ao fim de cada dia de trabalho tudo aquilo que não prejudique a sua continuação. 
II - Fale do que escreveu, se quiser, mas não leia nada a ninguém enquanto o trabalho estiver em curso. Toda a satisfação que daí possa retirar retardará o seu ritmo. Seguindo esse regime, o desejo crescente de comunicação acabará por ser um estímulo à conclusão.

III - Quanto às condições de trabalho, procure fugir à mediocridade da vida cotidiana. O meio sossego, acompanhado de ruídos pouco estimulantes, é degradante. Já o ruído de fundo de um estudo musical ou da confusão de vozes pode ser tão importante para o trabalho quanto o silêncio tangível da noite. Se este afina o ouvido interior, aqueles se tornam pedra de toque de uma dicção cuja riqueza consegue absorver em si até esses ruídos excêntricos.

IV - Evite servir-se do primeiro instrumento de trabalho que tenha à mão. É útil o apego pedante a determinados tipos de papel, canetas, tintas. Sem luxos, mas com a indispensável abundância desses utensílios.

$\mathrm{V}$ - Não deixe que nenhum pensamento passe por você incógnito, e use o seu bloco de notas com o mesmo rigor com que os serviços oficiais fazem o registro dos estrangeiros.

VI - Torne a sua caneta avessa à inspiração, e ela a atrairá a si com a força de um ímã. Quanto mais refletir antes de passar a escrito uma intuição, tanto mais amadurecida ela se te oferecerá. A fala conquista o pensamento, mas a escrita domina-o.

VII - Nunca deixe de escrever pelo fato de não o ocorrer mais nada. Um dos mandamentos da honra literária é o de interromper a escrita apenas quando há de respeitar uma hora marcada (uma refeição, um encontro) ou quando damos o trabalho por terminado.

VIII - Preencha os momentos de falta de inspiração passando a limpo o que já escreveu. Entretanto, a inspiração despertará.

IX - Nulla dies sine linea - mas semanas sim.

$\mathrm{X}$ - Nunca dê uma obra por acabada sem ter mergulhado nela uma vez mais, desde o serão até o nascer do dia.

XI - Não escreva a conclusão do trabalho no lugar onde habitualmente trabalha. Aí, perderia a coragem de fazê-lo.

XII - Graus da elaboração da obra: pensamento - estilo - escrita. A finalidade do passar a limpo é a de que agora toda a atenção se concentre na caligrafia. $\mathrm{O}$ pensamento mata a inspiração, o estilo aprisiona o pensamento, a escrita recompensa o estilo.

XIII - A obra é a máscara mortuária da sua concepção. (BENJAMIN, 2013, p. 27) 
A convocatória benjaminiana, que pode nos acenar um certo espanto agressivo, por uma vertigem quase "manualesca", 1 traz também, no respiro entre parágrafos, uma máxima quase comovente, como nos diria Gonçalo M. Tavares: "não tires os olhos do pensamento, ele precisa de ti" (TAVARES, 2013, p. 25). Aqui, parafrasearíamos: "não tires os olhos da escrita, ela precisa de ti".

Essa pequena sustentação de um cotidiano de proximidade com a palavra, aberta na lateralidade de um brandar da Primeira Guerra Mundial, parece nos fornecer rastros para armar pequenas fixações transitórias dentro da linguagem, que pensamos aqui se constituir como uma pergunta sobre o pesquisar, sobre um modo de anunciar nossos impasses na micropolítica do obrar a vida cotidiana, especialmente nos margeares as experimentações em saúde e educação.

Talvez por $i s s o,{ }^{2}$ destacamos quatro elementos que parecem produzir suas pernas de silêncio no entrelinhas da proposta de Benjamin:

$$
\begin{array}{r}
\text { gesto, } \\
\text { espaçamento, } \\
\text { memória, } \\
\text { tempo. }
\end{array}
$$

Gesto, que habita o tecido da temporalidade; tempo, que só se marca em espaçamento; memória, efeito dos traços/rastros, fazendo do tempo, gerúndio.

Pequenas mônodas, numa tentativa de "despossuir uma linha de separação entre o que é real, tido como mundo objetivo, e linguagem, tida como condição ficcional, inventiva. Essas casas do há, essas casas como zona de fronteira entre intimidade e profanação, como diz [Maria Gabriela] Llansol, nos faz encontrar arte nos restos humanos" (LIMA, 2005, n. p.). Mônodas que nos fazem localizar a prevalência de um "Há" no intervalo, no rastro de um gesto, na memória.

Se apostamos nas formulações freudiana ${ }^{3}$ e derridiana, ${ }^{4}$ segundo as quais a memória se funda na conjugação de um intervalo, de uma marca que se registra, espaça, reencontra o traço, que, já em abandono de uma origem, compõe com este que chega, firmamos, também, um certo margeio disruptivo com a cronologia, com a linearidade como régua exclusiva de uma narratividade, de percurso de pesquisa. 


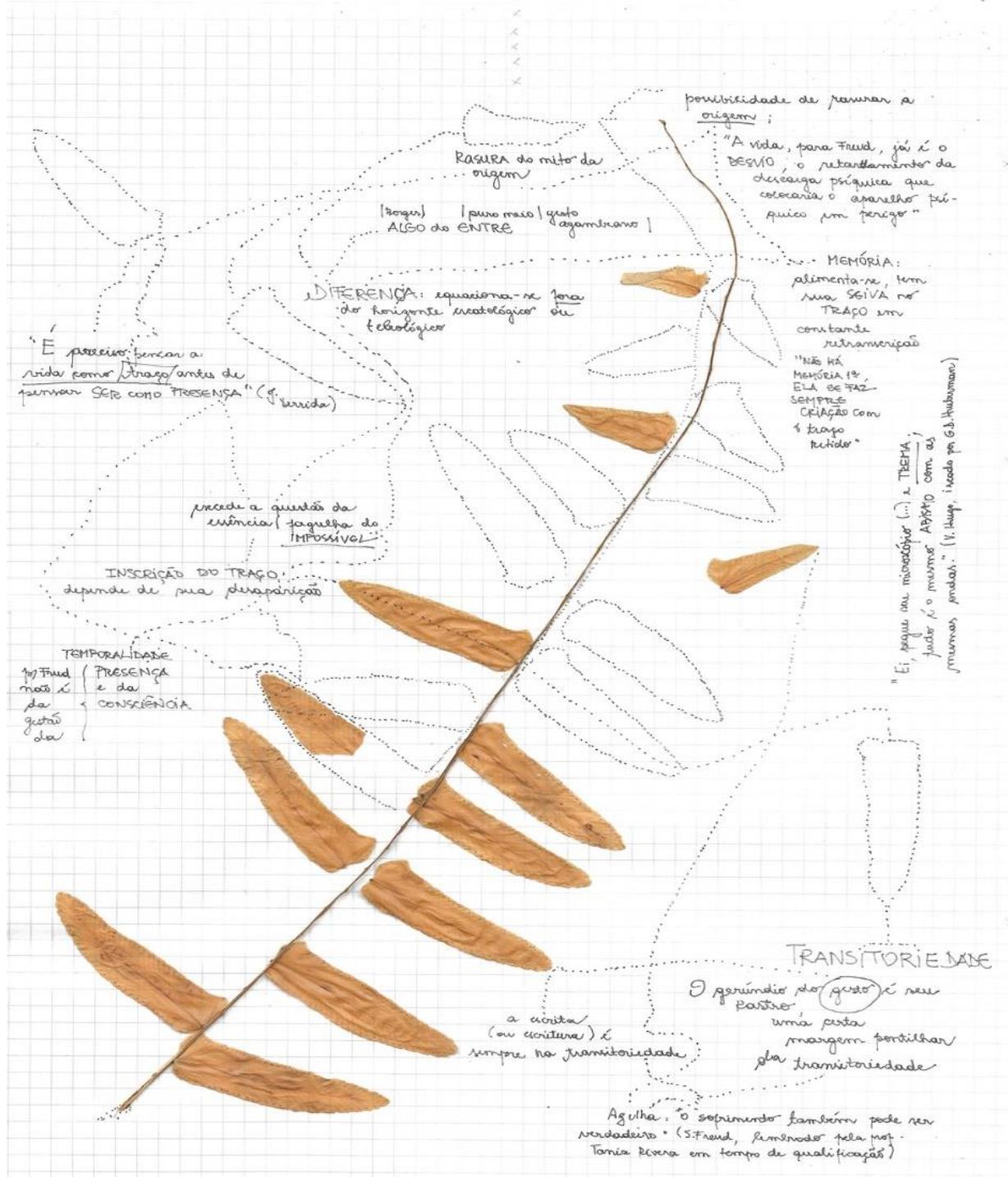

Mapa gestual II: experimentações com o pontilhar da transitoriedade e dos rastros do gesto.

Fonte: Gesto, Rastro, Memória: anotações para pensar uma ética da delicadeza. Dissertação de Mestrado UFRGS, 2018. Disponível em: http://hdl.handle.net/10183/181322

Diz-nos Gonçalo M. Tavares: dentro de nosso momento atual, o contemporâneo, temos, ao modo ventilado por Benjamin, uma possibilidade de definir começos, de saltar. Salto que pode se encontrar, num intervalo de poucas horas (ou minutos, nos casos de leitores mais hiperativos), com um escrito acadiano e uma poesia de 2018 , pontilhando mais de trinta séculos de intervalo temporal do escrito ao gesto de leitura.

Tocado por Hannah Arendt, Tavares escreve que "a intensidade da influência não depende das datas e sim da força da emissão, cruzada com o momento reflexivo do receptor" 
(TAVARES, 2013, p. 36). Ele o afirma como que nos situando que o aprender vai se produzir na demora possível de habitar o tempo de encontro com a leitura. Arendt nos alarga assinalando que houve uma conversão de "sucessão no tempo em justaposição espacial, de forma que a proximidade ou a distância deixaram de ser função dos séculos que nos separam de um filósofo, para passarem a depender exclusivamente do ponto livremente escolhido" (TAVARES, 2013, p. 36). Livremente, quem sabe, dentro do método da associação livre ${ }^{5}$ que a psicanálise nos ensina, nos ditames de uma casa onde Há o Isso, que interrompe, descontinua, movimenta.

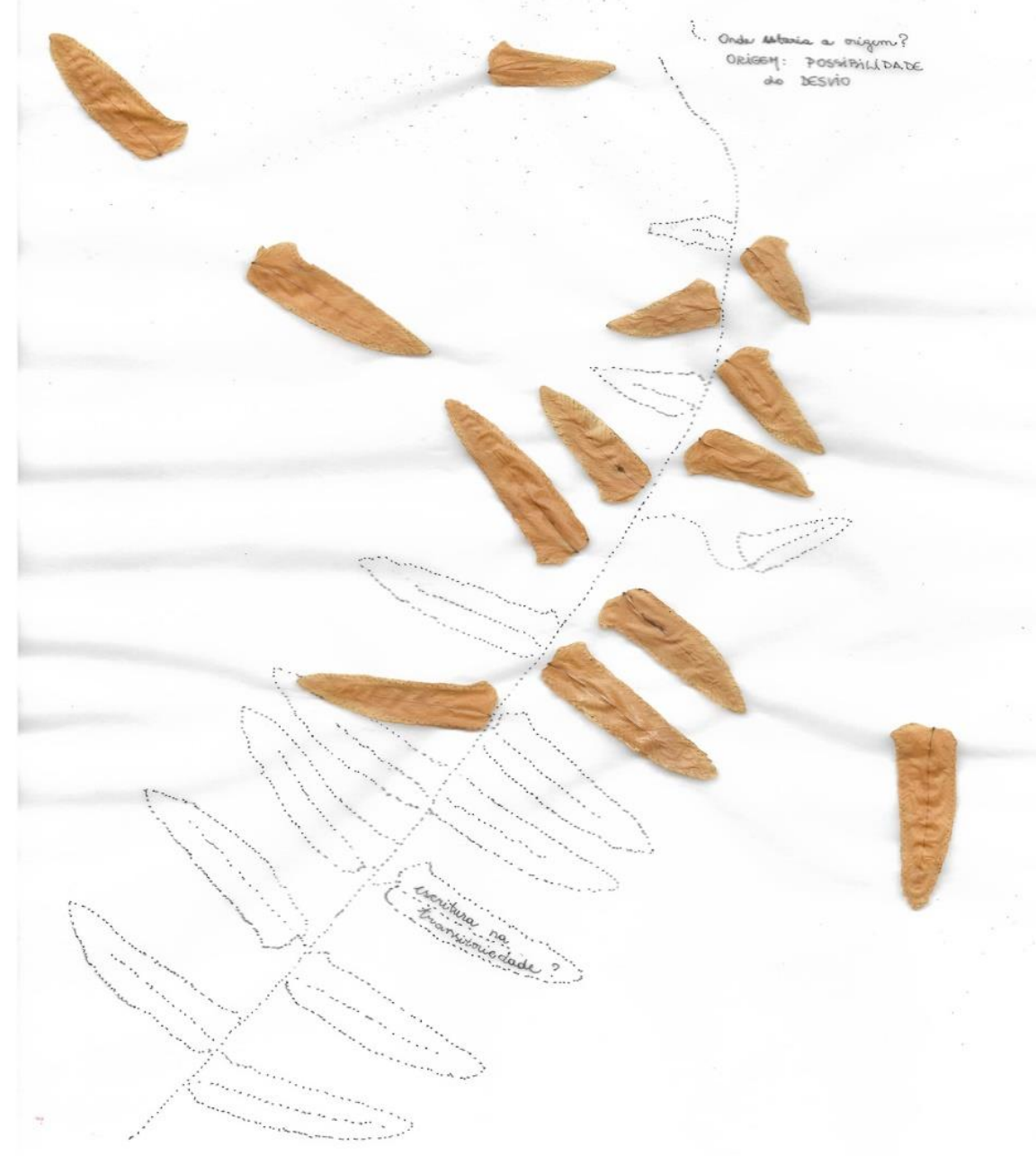

Mapa gestual III: em folha vegetal, experimentações sobre a ficcionalização da origem, do escrever na transitoriedade.

Fonte: Gesto, Rastro, Memória: anotações para pensar uma ética da delicadeza. Dissertação de Mestrado UFRGS, 2018. Disponível em: http://hdl.handle.net/10183/181322 
Na suspensão de cronologia, numa aposta de força no fragmento, no espaçamento, para pensar percursos de um pesquisar com o desejo, a obra do escritor português Gonçalo M. Tavares, intitulada Breves notas sobre a literatura-Bloom: dicionário literário, dentro da sua coleção Enciclopédia, ainda inédita no Brasil, chega-nos ensinante, aversada, inspiradora.

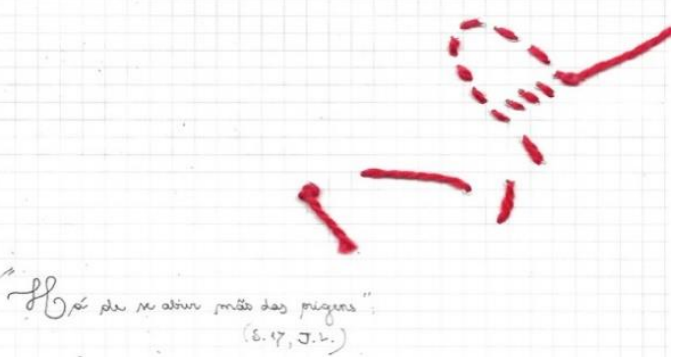

Mapa gestual IV: experimentações sobre a ficcionalização da origem, em bordado.

Fonte: Gesto, Rastro, Memória: anotações para pensar uma ética da delicadeza. Dissertação de Mestrado UFRGS, 2018. Disponível em: http://hdl.handle.net/10183/181322

Gonçalo M. Tavares já foi narrado, por José Saramago, como um escritor que funda uma forma textual bastante singular. Saramago anunciaria: "há um Antes e Depois de Gonçalo", quem sabe, anedotiando com nossa narratividade temporal de origens calcada na tradição cristã. De fato, Tavares parece ter a coragem do salto. Sua vasta composição de escrita passeia por diversos modos de experimentação na linguagem e, em cada um, algo do enunciado "há de se abrir mão das origens" parece ganhar textura, corporeidade. 
A publicação Breves notas sobre a literatura-Bloom chega no a posteriori de outros quatro títulos, chamados Breves notas sobre ciência, Breves notas sobre o medo, Breves notas sobre as ligações e Breves notas sobre música. A estrutura da anotação, nessa condição de possibilidade de abertura a acolher um novo registro, sussurra-nos os ventos da aposta freudiana sobre a estrutura da memória, com a imagem fornecida por Sigmund Freud em 1925, via Bloco Mágico.
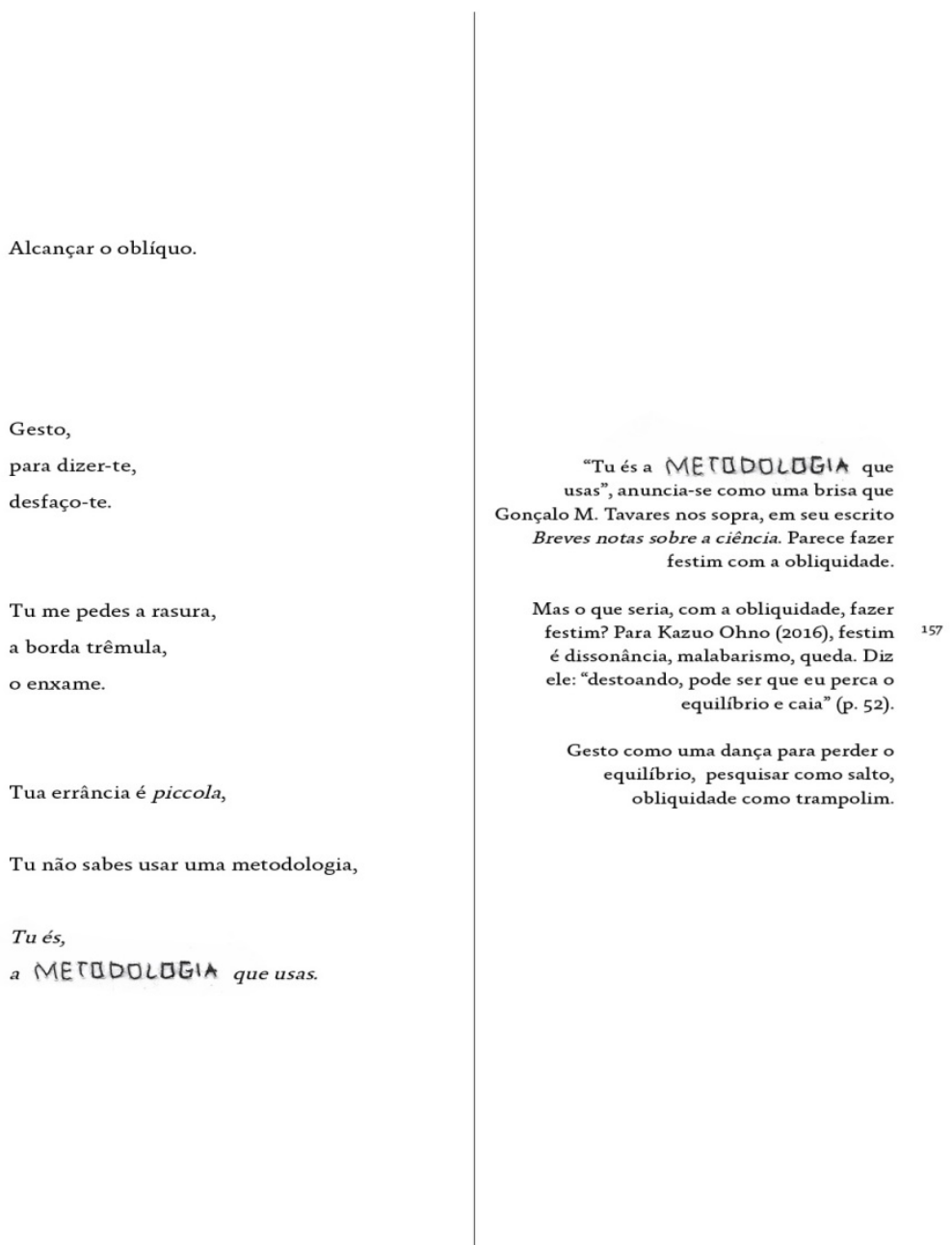

Fragmento da dissertação Gesto, rastro, memória: anotações para pensar uma ética da delicadeza, que compõe um percurso extenso sobre a pergunta que liga o gesto ao pesquisar.

Fonte: Gesto, Rastro, Memória: anotações para pensar uma ética da delicadeza. Dissertação de Mestrado UFRGS, 2018. Disponível em: http://hdl.handle.net/10183/181322

Freud, para seguir respondendo à pergunta sobre as marcas mnêmicas e a memória, aloca a pequena plaquinha de cera, coberta de finas camadas de papiro, como imagem possível 
para nos aproximarmos da radicalidade da natureza ficcional da vida e, em efeito, de nossa memória. Ao modo de um tempero freudiano, parece-nos que Tavares também, com sua provocação de uma coleção intitulada Enciclopédia, ajuda no corte, permite furar o manto das versões mais totalitárias da linguagem que cada um, cada uma de nós, ao seu modo, pode produzir. Se tomarmos uma enciclopédia como a suposta tentativa de recobrir a totalidade dos termos da cultura, sua metabolização literária via uso de notas breves dá-nos a chance de uma experiência ativa como leitores/leitoras, pois a anotação como conjugação aberta produz um ritmo que inclui perspectivas, pontos-de-vista, devaneios... Como se a anotação, em sua transitoriedade infinitiva, lembrasse que um método-caminho se faz com presença, corporeidade.

Agregando ainda uma peculiaridade, o escritor português produz uma certa dicionarização, também em recorte de uma vertigem de totalização que o dicionário pode convidar, do que elenca como palavras-sulco para uma literatura-Bloom. Diz, em "Nota Inicial":

[...] há infinitas maneiras (definitivas) de fazer literatura. Este é um Dicionário da literatura-Bloom. Podemos ser definidos numa direcção uma vez, e depois, na vez seguinte, ser definitivos, completamente, entusiasmaticamente, mas noutra direcção. Noutros lados, claro, sigo por vezes percursos inimigos e velocidades diferentes $[\ldots]$. De facto, talvez nem mesmo este dicionário seja um Bloom-puro. E assim parece-me que está bem. (TAVARES, 2018, p. 11)

Encontra-se, nas Breves notas referidas, uma lista de sessenta e uma palavras, entre as letras A e V. Colocamos "entre", pois nosso alfabeto português não está sequencialmente contemplado. É nesse vazio instaurado que podemos também inventar modos distintos de pensar, de imaginar. Por exemplo, da letra I, com última dicionarização com a palavra "Invenção", salta-se para a L, com a auspiciosa escolha da palavra "Legislação". O que se ficcionaliza na letra do legislar? O que entremeia o J, o K, suprimidos? Como nos gesta Giorgio Agamben, "o verdadeiro lugar da poesia não estaria por acaso nem numa página nem noutra, mas no espaço vazio entre elas?"(AGAMBEN, 2018, p. 110).

Acompanhemos a letra T, que se aloca com as palavras "Tangente" e "Técnica". Na tangente, parece que o escritor nos ajuda a margear o oblíquo, na possibilidade que instaura de engordar nossas redes simbólicas, com voltas de acalanto contingente, ao encontro mais brutal com o que, psicanaliticamente, entoamos como Real.

Por "Tangente", define: "qualquer ligeiro toque poderá ser brutal. A delicadeza é apenas um dos modos de não matar. Qualquer frase-Bloom deverá traçar uma tangente às outras frases. Porém, a ligação não será narrativa." (TAVARES, 2018, p. 75). E por "Técnica":

[...] não é um massacre do espontâneo; a técnica é ter consciência do espontâneo [...]. A técnica não é um cão dócil. Se a técnica é um animal doméstico, então deita fora desta técnica. Toda frase que resulta de uma batalha, mesmo que breve, é mais forte do que a frase que resulta de um contrato. Deverás apenas usar as 
técnicas que te tornam imperfeito. Todo imperfeito é um início. (TAVARES, 2018, p. 76)

Ao mesmo modo das técnicas de escrita de uma tese, ritmadas com Benjamin, Gonçalo M. Tavares toca num estilo de linguagem que poderíamos, talvez mais apressadamente, contornar como imperativo. Mas aqui, mais uma vez, a verbalização imperativa não parece querer enclausurar o pensamento - um sentido mais costumeiro da voz imperativa -, e sim, em avesso, dar lugar ao tempo em suspensão. Como nos lembraria Giorgio Agamben, numa referência à Émile Benveniste, "o imperativo, na verdade, não tem caráter temporal" (AGAMBEN, 2018, p. 49).

Tavares, em suas breves notas dicionarescas, parece nos dar um relicário de gestos, num jogo de transitoriedades que desajusta, "custodia metamorfoses".

Talvez seja um encontro de transformar o ribeirão em braço de mar, dar à palavra brasa, asas, tal qual Perseu, que em seus pés alados, como nos lembraria Italo Calvino (2002), corta a cabeça de Medusa. Inevitável a rede de acumulações, ampliação do campo de complexidades, cabendo a cada leitor/a a montagem, a combinação e a despossessão de sentidos.

Como compassa em posfácio Borja Bagunya, não se trata de "encontrar novos objetos para a escrita, mas aprender a ver a possibilidade em tudo aquilo que se nos impõe como definitivo, de encontrar ardor do movimento na quietude" (BAGUNYA, 2018, p. 87).

Errância inspiradora para nossas pesquisas e experiências micropolíticas em saúde e educação, nas quais, por vezes, o ardor da Adiposidade ${ }^{6}$ das barbáries cotidianas faz-nos esquecer de uma diretriz fundamental, dicionarizada na palavra "Andaime": "não olhes para mim quando eu chegar; olha para mim quando eu avançar” (TAVARES, 2018, p. 16). Apostar no que talvez seja uma anunciação subversivamente delicada e, por isso, radical: saltar supondo companhia, pesquisar deixando aberto o campo para que a transitoriedade dos gestos cotidianos se pontilhe, inocule, com o areiar do tempo, seu ferrão. Partilhar o impasse de uma situação de atendimento em saúde, por exemplo, das redes de atenção à saúde, educação que por vezes quase se enforca, e, no gestar de escrever sobre isso que quase se vai, encontrar, exatamente nesse abismo, o que pode nos aproximar. Diria-nos a escritora polonesa Wislawa Szymborska: "O abismo não nos divide./ O abismo nos cerca." (SZYMBORSKA, 2012, n. p.).

Uma leitura-convite que abre a janela a uma política com a imaginação, a seguir fareliando gestos e, com as imparidades do encontro com o outro, viver juntos. 


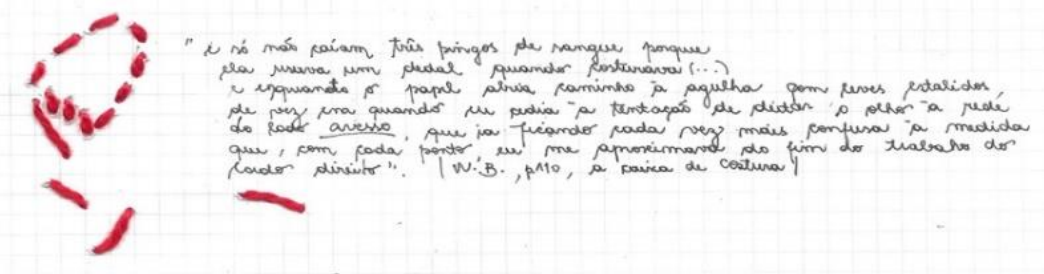

Mapa gestual V: experimentação em gesto, no avessar a linguagem.

Fonte: Gesto, Rastro, Memória: anotações para pensar uma ética da delicadeza. Dissertação de Mestrado UFRGS, 2018. Disponível em: http://hdl.handle.net/10183/181322

\section{Notas}

1. Manualesca: neologismo inspirado no encontro subversivo que a poesia de Manoel de Barros compõe com a linguagem, propondo que as palavras encontrem um alargamento de sentidos.

2. Isso: termo-em-tradução na linguagem psicanalítica: Isso, em alemão (Es), constitui a forma de nomear o que foi traduzido como $I d$, inconsciente. 
3. A pergunta sobre a estrutura lógica da memória e a plataforma de inscrição psíquica atravessa a obra de Sigmund Freud. Aqui, detemo-nos em dois trabalhos: Projeto para uma psicologia científica (1895) e Notas sobre o "Bloco Mágico" (1925).

4. Conforme Jacques Derrida desenvolve no texto "Freud e a cena da escritura", presente no livro A escritura e a diferença (1979).

5. A associação livre é determinada por um obrar inconsciente, não é possível ser controlada ou vislumbrada em um $a$ priori.

6. No dicionário gonçalesco, sobre a "Adiposidade": "há frases adiposas, frases com barriga. Uma palavra-adiposa é uma palavra que não avança” (TAVARES, 2018, p. 15).

\section{Referências}

AGAMBEN, Giorgio. O fogo e o relato: ensaios sobre criação, escrita, arte e livros. São Paulo: Boitempo, 2018.

BAGUNYA, Borja. Literatura-Bloom. In: Tavares, Gonçalo M. Breves notas sobre literatura-Bloom. Lisboa: Relógio d'Água, 2018. p. 81-87.

BENJAMIN, Walter. Técnica do escritor em 13 teses. In: Rua de mão única: infância berlinense: 1900. Belo Horizonte: Autêntica Editora, 2013. p. 67-116.

CALVINO, Italo. Seis propostas para o próximo milênio. São Paulo: Companhia das Letras, 2002.

DERRIDA, Jacques. Freud e a cena da escritura. In: . A escritura e a diferença. São Paulo: Perspectiva, 2014. p. 289-338.

LIMA, Manoel Ricardo de. Entrevista com Manoel Ricardo de Lima. Maria João Cantinho - Site pessoal. Lisboa, 2005. Disponível em: <https://mjcantinho.com/2016/03/07/entrevista-com-manoel-ricardo-delima/>. Acesso em: 27 nov. 2018.

FREUD, Sigmund. Notas sobre o "Bloco Mágico". In: 1925). São Paulo: Companhia das Letras, 2011. p $\overline{267-274}$.

Projeto para uma psicologia científica. In: O eu e o id, autobiografia e outros textos (1923completas de Sigmund Freud, v. 1. São Paulo: Imago, 1988. p. 335-454.

SZYMBORSKA, Wislawa. Autonomia. Modo de usar \& co. Disponível em: $<$ http://revistamododeusar.blogspot.com/2012/02/wislawa-szymborska-1923-2012.html>. Acesso em: 27 nov. 2018.

TAVARES, Gonçalo M. Atlas do corpo e da imaginação. Lisboa: Editorial Caminho, 2013.

. Breves notas sobre literatura-Bloom. Lisboa: Relógio d’Água, 2018.

\section{Correspondência}

Anna Leticia Ventre: Tem graduação em Psicologia pela Universidade do Vale do Rio dos Sinos (2005), pós graduações nas áreas de saúde pública (2008-2009), saúde mental (2009-2010) e infância e adolescência (2010-2011). Percurso em Psicanálise pela Associação Psicanalítica de Porto Alegre (2012-2015). Mestrado em Psicanálise: Clínica e Cultura (2016 -2018). Atua no NUPPEC - Núcleo de Pesquisa em Psicanálise, Educação e Cultura - UFRGS.

E-mail: annaleticiaventre@gmail.com 
Simone Zanon Moschen: Tem Mestrado em Educação pela Faculdade de Educação/UFRGS (1997) e Doutorado em Educação pela Faculdade de Educação/UFRGS (2002). Pós-doutorado em Psicanálise pela UERJ (2011). É Professora do Departamento de Psicanálise e Psicopatologia do Instituto de Psicologia da Universidade Federal do Rio Grande do Sul (UFRGS) e dos Programas de Pós-graduação em Psicanálise: Clínica e Cultura (UFRGS) e de Educação (UFRGS). É Bolsista de Produtividade em Pesquisa 2 do CNPq e Coordenadora substituta do Programa de Pós-graduação em Psicanálise: Clínica e Cultura. Co-coordenadora do NUPPEC (Núcleo de Psicanálise, Educação e Cultura CNPq/UFRGS).

E-mail: simoschen@gmail.com

Texto publicado em Currículo sem Fronteiras com autorização dos autores 